\title{
Association between Industry Payments and Scholarly Impact among Academic Ophthalmologists
}

\author{
Michael Solotke, BS ${ }^{1}$ Susan Forster, MD $^{2}$ Jessica Chow, MD $^{2}$ Jenesis Duran ${ }^{3}$ Hasna Karim ${ }^{3}$ \\ Victoria Marks ${ }^{3}$ Shireen Roy ${ }^{3}$ Ashlynn Torres ${ }^{3}$ Ron Adelman, MD, MBA ${ }^{2}$ \\ 1 Yale University School of Medicine, New Haven, Connecticut \\ 2 Department of Ophthalmology and Visual Science, Yale University \\ School of Medicine, New Haven, Connecticut \\ 3 Yale College, New Haven, Connecticut \\ J Acad Ophthalmol 2019;11:e1-e8. \\ Address for correspondence Michael Solotke, BS, Yale University \\ School of Medicine, 367 Cedar Street, New Haven, CT 06510 \\ (e-mail: michael.solotke@yale.edu).
}

\begin{abstract}
Keywords

- conflict of interest

- health policy

- industry payments

Purpose The aim of this article is to examine the association between industry payments to ophthalmologists and scholarly impact.

Design Retrospective cross-sectional study.

Methods All ophthalmology faculty at United States accredited ophthalmology residency programs were included in this study. The main exposure was industry payments to ophthalmologists in 2016, as reported in the Centers for Medicare and Medicaid Services Open Payments Database. The primary outcome was Hirsch index (H-index), a measure of scholarly impact.

Results Among 1,653 academic ophthalmologists in our study, 1,225 (74\%) received industry payments in 2016. We did not observe a difference between the mean $\mathrm{H}$-index of ophthalmologists receiving any industry payments versus those not receiving any payments $(p=0.68)$. In analysis including only ophthalmologists who received industry payments, $\mathrm{H}$-index differed significantly by payment amount: 12.6 for ophthalmologists receiving less than $\$ 100,12.2$ for those receiving $\$ 100$ to 1,000 , 18.8 for those receiving $\$ 1,000$ to $10,000,21.3$ for those receiving $\$ 10,000$ to 100,000 , and 29.4 for those receiving greater than $\$ 100,000(p<0.001)$. Within each academic rank and gender, industry payments greater than $\$ 1,000$ were associated with a higher H-index $(p<0.05)$.

Conclusions Although our analysis cannot prove causality, we observed a significant association between industry payments and scholarly impact among academic ophthalmologists, even after adjusting for gender, academic rank, and subspecialty. Prospective studies should further evaluate this relationship.
\end{abstract}

While financial relationships between physicians and manufacturers of pharmaceuticals and medical devices have long existed, these relationships have recently come under increasing scrutiny due to concerns of impact on physicians' prescribing patterns. To address these concerns, the Physician Payments Sunshine Act was enacted in 2010, requiring manufacturers to report to the Centers for Medicare and Medicaid
Services (CMS) any payments made to physicians totaling over $\$ 100$ per year. ${ }^{1}$ It also required the creation of the Open Payments Program, which makes these data publicly available. ${ }^{2}$

The improved transparency from this program has facilitated initial investigations into who receives money from industry, as well as implications of these payments. Several studies have examined the relationship between industry received

November 14, 2018 accepted after revision December 11, 2018
DOI https://doi.org/

10.1055/s-0039-1677681. ISSN 2475-4757.
Copyright $\odot 2019$ by Thieme Medical Publishers, Inc., 333 Seventh Avenue, New York, NY 10001, USA. Tel: +1(212) 584-4662.
License terms

(요 (1) $\Theta$ 
payments and research output, revealing a connection between receiving payments and increased scholarly impact. $^{3-7}$ In the field of ophthalmology, industry payments have been associated with distinct patterns in prescribing of antivascular endothelial growth factor (VEGF) agents, prompting questions about the impact of these payments on ophthalmologists. ${ }^{8,9}$

To broaden the understanding of industry payments to ophthalmologists, we conducted a comprehensive analysis of Open Payments data for every academic ophthalmologist in the United States, examining associations between industry support and scholarly impact. We also analyzed the influence of subspecialty, gender, academic rank, type of degree, and additional degree(s) (e.g., MBA, MPH) on scholarly output. As ophthalmologists with high scholarly impact are considered academic leaders and are often asked to serve on guideline committees or lead practice-determining clinical trials, an understanding of these dynamics is a critical step toward increasing transparency and research integrity in ophthalmology.

\section{Methods}

\section{Study Sample}

Our sample consisted of ophthalmology faculty included on publicly available web sites of all 117 accredited ophthalmology residency programs in the continental United States, as listed by the Accreditation Council for Graduate Medical Education. ${ }^{10}$ Using the web sites for each of these residency programs, the following information was extracted for each ophthalmologist: name, gender, primary medical degree (MD, DO, MD/PhD), presence of additional degree(s) (binary variable; included degrees such as MBA, MPH, and MHS), and academic rank (assistant professor, associate professor, full professor). Subspecialty data were collected from the American Academy of Ophthalmologists (AAO) "Find an Ophthalmologist" database and from faculty webpages. ${ }^{11}$

We excluded faculty without an MD or DO degree, as reporting requirements apply to physicians only. ${ }^{12}$ We also excluded ophthalmologists whose title was not one of the following: assistant professor, associate professor, or professor. Ophthalmologists whose appointment specified a primarily clinical role (e.g., "Clinical Associate Professor") were excluded, as we assumed that research may not be a primary component of their responsibilities. We also excluded ophthalmology faculty members from military training programs and from programs located outside of the continental United States. Ophthalmologists whose most recent publication was more than 10 years before 2016 were also excluded, because we assumed that these ophthalmologists were no longer actively involved in research. Finally, ophthalmologists for whom subspecialty data could not be located were excluded from the subspecialty analysis only.

\section{Payments to Physicians}

Industry payments to ophthalmologists were identified using the CMS Open Payments Database for the year 2016, ${ }^{2}$ which was the most recent year available at the time of data collection for this study. The Open Payments Database makes information about financial relationships between physicians and certain healthcare manufacturers publicly available. Payments of the following types were recorded for each ophthalmologist: general payments (i.e., payments not associated with research), research payments (i.e., payments associated with a research agreement or protocol), physician ownership or investment interest (i.e., value of ownership or investment interest in certain healthcare manufacturers), and associated research funding (i.e., payments to a research institution that name the physician as a principal investigator). ${ }^{13}$ Total payments received by each ophthalmologist were divided into the following payment categories, consistent with those used in a previous analysis of the Open Payments data: less than $\$ 100, \$ 100$ to $1,000, \$ 1,000$ to $10,000, \$ 10,000-100,000$, and greater than $\$ 100,000{ }^{4}$ General payments were also grouped into the following types: food and beverage, education, consulting, speaker at a Continuing Education Program (CEP), speaker at a non-CEP, travel and lodging, honorarium, entertainment, gifts, and other (e.g., charitable contributions, royalty, or license fees).

\section{Outcome Variables}

To assess the overall scholarly impact of each ophthalmologist, bibliometric data were extracted using the "Author Search Tool" from Scopus. ${ }^{14}$ Scopus is a database of peerreviewed literature with information about citations. The following data were extracted for each ophthalmologist: Hirsch index (H-index), total number of documents, total citations, and range of publication activity (in years). $\mathrm{H}$-index is a validated marker of scholarly impact, defined by having published $\mathrm{h}$ publications with at least $\mathrm{h}$ citations per publication. ${ }^{15}$ For example, a physician with an $\mathrm{H}$-index of 30 has published at least 30 publications with at least 30 citations each. This metric has been shown to be a better measure of the overall quality and quantity of a scientist's research than other variables, such as total citations or total publications. ${ }^{16}$

\section{Statistical Analysis}

Descriptive statistics were used to characterize the sample. We used analysis of variance and two-sided unpaired $t$-tests for comparison of continuous variables. A p-value of 0.05 was used for all statistical tests. All analyses were performed using Stata 15.0 and outputs were displayed with GraphPad Prism 7.0. Institutional Review Board approval was obtained from the Yale University Institutional Review Board.

\section{Results}

\section{Academic Ophthalmologists}

There were 1,653 academic ophthalmologists that met inclusion criteria for our study (-Table 1). Of these ophthalmologists, 1,104 (67\%) were men and 549 (33\%) were women. Academic rank was assistant professor for 649 (39\%), associate professor for 392 (24\%), and full professor for 612 (37\%). The most common subspecialties were surgical retina (17\%), glaucoma (14\%), cornea/external disease (13\%), and pediatric ophthalmology/strabismus (11\%). Additional degrees such as MPH and MBA were identified for 140 (8\%) academic ophthalmologists. 
Table 1 Characteristics of academic ophthalmologists receiving industry payments and amount of payments received

\begin{tabular}{|c|c|c|c|}
\hline Ophthalmologist characteristic & $\begin{array}{l}\text { Number of } \\
\text { ophthalmologists } \\
\text { (\% of total) }\end{array}$ & $\begin{array}{l}\text { Number of } \\
\text { ophthalmologists } \\
\text { paid (\% of category) }\end{array}$ & $\begin{array}{l}\text { Mean payment } \\
\text { (standard error of mean), } \\
\text { in thousands of dollars a }\end{array}$ \\
\hline \multicolumn{4}{|l|}{ Gender } \\
\hline Male & $1,104(67)$ & $842(76)$ & $34.7(5.7)$ \\
\hline Female & $549(33)$ & $383(70)$ & $15.1(5.7)$ \\
\hline \multicolumn{4}{|l|}{ Academic rank } \\
\hline Assistant professor & 649 (39) & $478(74)$ & $6.7(1.5)$ \\
\hline Associate professor & $392(24)$ & $283(72)$ & $22.2(3.9)$ \\
\hline Full professor & $612(37)$ & $464(76)$ & $55.0(11.0)$ \\
\hline \multicolumn{4}{|l|}{ Primary Degree } \\
\hline $\mathrm{MD}$ & $1,404(85)$ & $1,067(76)$ & $29.5(4.9)$ \\
\hline $\mathrm{MD} / \mathrm{PhD}$ & $230(14)$ & $150(65)$ & $22.0(4.6)$ \\
\hline $\mathrm{DO}$ & $19(1)$ & $8(42)$ & $29.8(29.6)$ \\
\hline \multicolumn{4}{|l|}{ Additional degree(s) $^{\mathrm{b}}$} \\
\hline Yes & $140(8)$ & $98(70)$ & $29.5(4.7)$ \\
\hline No & $1,513(92)$ & $1,127(74)$ & $18.5(5.3)$ \\
\hline \multicolumn{4}{|l|}{ Subspecialty } \\
\hline Cataract/anterior segment & $44(3)$ & $40(91)$ & $27.0(11.4)$ \\
\hline Comprehensive & $100(6)$ & $77(77)$ & $4.5(1.8)$ \\
\hline Cornea/external disease & $208(13)$ & $175(84)$ & $16.2(4.2)$ \\
\hline Glaucoma & $229(14)$ & $187(82)$ & $35.5(12.0)$ \\
\hline Neuro-ophthalmology & $123(7)$ & $70(57)$ & $30.9(20.0)$ \\
\hline Ocular Oncology & $24(1)$ & $17(71)$ & $6.6(5.2)$ \\
\hline Oculoplastics & $133(8)$ & $109(82)$ & $2.2(1.0)$ \\
\hline Ophthalmic pathology & $25(2)$ & $11(44)$ & $0.5(0.3)$ \\
\hline Pediatric/strabismus & $190(11)$ & $106(56)$ & $4.5(1.8)$ \\
\hline Refractive surgery & $19(1)$ & $18(95)$ & $15.3(9.4)$ \\
\hline Medical retina & $68(4)$ & $52(76)$ & $26.8(10.5)$ \\
\hline Surgical retina & $284(17)$ & $243(86)$ & $57.8(14.1)$ \\
\hline Uveitis/immunology & $36(2)$ & $29(81)$ & $33.0(15.0)$ \\
\hline Other & $33(2)$ & $12(36)$ & $62.9(39.0)$ \\
\hline Subspecialty not identified & $137(8)$ & $79(58)$ & $46.7(34.7)$ \\
\hline
\end{tabular}

Notes: Authors' analysis of data from open payments database.

aExcludes individuals who did not receive any industry funding.

Includes MD, DO, and MD/PhD ophthalmologists.

\section{Payments to Academic Ophthalmologists}

Of the 1,653 academic ophthalmologists in our sample, 1,225 (74\%) received industry payments in 2016, totaling $\$ 35.0$ million. The majority of this funding was in the form of general payments ( $\$ 18.9$ million, $54 \%$ ) and associated research payments ( $\$ 13.1$ million, 37\%); the remaining payments were physician ownership (\$2.8 million, $8 \%$ ) and direct research payments ( $\$ 0.2$ million, $<1 \%$ ).

Among academic ophthalmologists who received any form of industry payment, the median payment amount was $\$ 265$ (interquartile range, $\$ 81-4,341$ ), and the mean was $\$ 28,582$. Of these ophthalmologists, 352 (29\%) received less than $\$ 100,468$ (38\%) received between $\$ 100$ and 1,000, 172 (14\%) received between $\$ 1,000$ and 10,000, $152(12 \%)$ received between $\$ 10,000$ and 100,000 , and $81(7 \%)$ received greater than $\$ 100,000$ (- Table 2). Payments totaling more than $\$ 10,000$ were received by males more commonly than females (22 vs $13 \%$ ), and by full and associate professors more commonly than assistant professors (27 vs $23 \%$ vs $8 \%$, respectively). Ophthalmologists in the following subspecialties most commonly received payments totaling more than $\$ 10,000$ : surgical retina (33\%), glaucoma (26\%), uveitis/ immunology (24\%), cataract/anterior segment (22\%), and other $(42 \%)$. 
Table 2 Distribution of industry payments received by academic ophthalmologists

\begin{tabular}{|c|c|c|c|c|c|}
\hline \multirow[t]{2}{*}{ Ophthalmologist characteristic } & \multicolumn{5}{|c|}{ Ophthalmologists receiving payments in each category: No. (\%) } \\
\hline & $<\$ 100$ & $\$ 100-1,000$ & $\$ 1,000-10,000$ & $\$ 10,000-100,000$ & $>\$ 100,000$ \\
\hline All ophthalmologists & $352(29)$ & $468(38)$ & $172(14)$ & $152(12)$ & $81(7)$ \\
\hline \multicolumn{6}{|l|}{ Gender } \\
\hline Male & $222(26)$ & $313(37)$ & $123(15)$ & $115(14)$ & $69(8)$ \\
\hline Female & $130(34)$ & $155(40)$ & $49(13)$ & $37(10)$ & $12(3)$ \\
\hline \multicolumn{6}{|l|}{ Academic rank } \\
\hline Assistant professor & $171(36)$ & $214(45)$ & $53(11)$ & $31(6)$ & $9(2)$ \\
\hline Associate professor & $72(25)$ & $108(38)$ & $37(13)$ & $46(16)$ & $20(7)$ \\
\hline Full professor & $109(23)$ & $146(31)$ & $82(18)$ & $75(16)$ & $52(11)$ \\
\hline \multicolumn{6}{|l|}{ Primary degree } \\
\hline MD & $317(30)$ & 415 (39) & $141(13)$ & $123(12)$ & $71(7)$ \\
\hline DO & $3(38)$ & $4(50)$ & $0(0)$ & $0(0)$ & $1(12)$ \\
\hline $\mathrm{MD} / \mathrm{PhD}$ & $32(21)$ & $49(33)$ & $31(21)$ & $29(19)$ & $9(6)$ \\
\hline \multicolumn{6}{|l|}{ Additional degree $(s)^{a}$} \\
\hline Yes & $23(23)$ & $33(34)$ & $22(22)$ & $15(15)$ & $5(5)$ \\
\hline No & $329(29)$ & 435 (39) & $150(13)$ & $137(12)$ & $76(7)$ \\
\hline \multicolumn{6}{|l|}{ Subspecialty } \\
\hline Cataract/anterior segment & $11(28)$ & $14(35)$ & $6(15)$ & $5(12)$ & $4(10)$ \\
\hline Comprehensive & $28(36)$ & $40(52)$ & $2(3)$ & $7(9)$ & $0(0)$ \\
\hline Cornea/external disease & $55(31)$ & $72(41)$ & $21(12)$ & $16(9)$ & $11(6)$ \\
\hline Glaucoma & $36(19)$ & $67(36)$ & $35(19)$ & 35 (19) & $14(7)$ \\
\hline Neuro-ophthalmology & $28(40)$ & $28(40)$ & $6(9)$ & $4(6)$ & $4(6)$ \\
\hline Ocular oncology & $6(35)$ & $8(47)$ & $1(6)$ & $2(12)$ & $0(0)$ \\
\hline Oculoplastics & $47(43)$ & $52(48)$ & $7(6)$ & $3(3)$ & $0(0)$ \\
\hline Ophthalmic pathology & $3(27)$ & $6(55)$ & $2(18)$ & $0(0)$ & $0(0)$ \\
\hline Pediatric/strabismus & $42(40)$ & $40(38)$ & $15(14)$ & $8(8)$ & $1(1)$ \\
\hline Refractive surgery & $2(11)$ & 7 (39) & $6(33)$ & $2(11)$ & $1(6)$ \\
\hline Medical retina & $20(38)$ & $11(21)$ & $11(21)$ & $5(10)$ & $5(10)$ \\
\hline Surgical retina & $39(16)$ & $77(32)$ & 47 (19) & 47 (19) & $33(14)$ \\
\hline Uveitis/immunology & $7(24)$ & $13(45)$ & $2(7)$ & $4(14)$ & $3(10)$ \\
\hline Other & $1(8)$ & $4(33)$ & $2(17)$ & $3(25)$ & $2(17)$ \\
\hline
\end{tabular}

Notes: Table showing proportion of academic ophthalmologists receiving different total payment amounts, and variations in this distribution by ophthalmologist characteristic.

ancludes MD, DO, and MD/PhD ophthalmologists.

\section{Association between Industry Payments and Scholarly Impact}

There was no statistically significant difference between the mean H-index of academic ophthalmologists receiving any industry payments and those not receiving any payments $(p=0.68)$. However, among academic ophthalmologists who did receive industry payments, there was a significant difference in $\mathrm{H}$-index by payment category $(p<0.001)(-$ Fig. 1$)$. The mean $\mathrm{H}$-index was 12.6 for ophthalmologists receiving less than $\$ 100,12.2$ for those receiving between $\$ 100$ and 1,000 , 18.8 for those receiving between $\$ 1,000$ and $10,000,21.3$ for those receiving between $\$ 10,000$ and 100,000 , and 29.4 for those receiving greater than $\$ 100,000$. These differences remained statistically significant when analyzing other bibliometric indicators, including total number of publications $(p<0.001)$ and total number of citations $(p<0.001)$.

In analysis examining general payments only, there was a significant difference in mean $\mathrm{H}$-index by general payment amount $(p<0.001)$. The most common general payment type was food and beverage, with 1,100 ophthalmologists (94\% of ophthalmologists receiving any general payment) receiving this type of payment ( - Table 3 ). Additionally, there was a significant difference between the mean $\mathrm{H}$-index of ophthalmologists receiving greater than $\$ 1,000$ versus less 

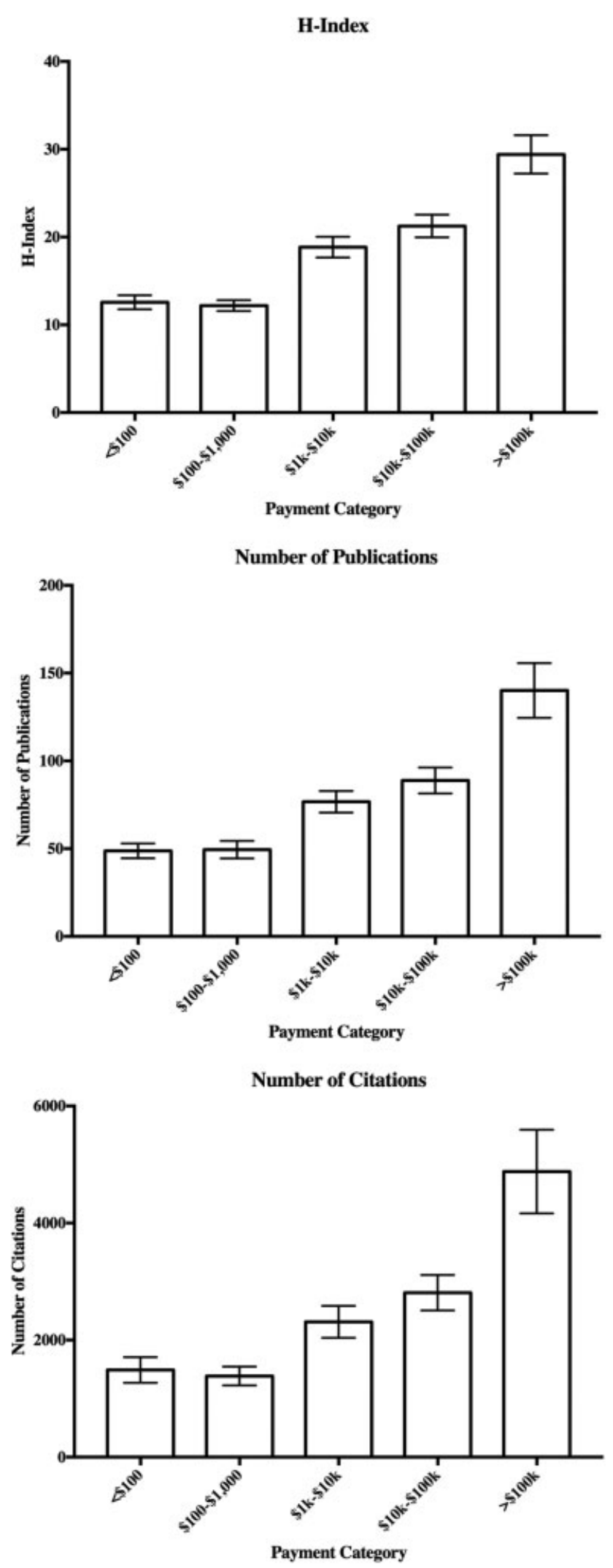

Fig. 1 Association between industry payments and scholarly impact. Notes: Bar graph showing authors' analysis of bibliometric data stratified by total industry payments received, with scholarly impact measured by (top) mean $\mathrm{H}$-index, (middle) mean number of publications, and (bottom) mean number of citations. Error bars indicate standard error of mean. than $\$ 1,000$ in the following general payment types: food and beverage $(p<0.001)$, travel and lodging $(p<0.001)$, non-CEP speaker fees $(p=0.02)$, and honoraria $(p=0.048)$.

\section{Subgroup Analysis}

-Fig. 2 summarizes the results of the subgroup analysis by gender, academic rank, degree(s), and subspecialty. Within each academic rank and gender, industry payments greater than $\$ 1,000$ were associated with a higher mean $\mathrm{H}$-index (-Fig. 2). This trend also held true for ophthalmologists whose only professional degree was MD and ophthalmologists with additional degrees such as MPH and MBA, but we did not observe the same dynamic for $\mathrm{MD} / \mathrm{PhDs}$. Additionally, this trend held true for ophthalmologists in the following subspecialties: cornea/external disease, glaucoma, neuro-ophthalmology, oculoplastics, pediatric ophthalmology/strabismus, and surgical retina.

\section{Discussion}

In this comprehensive analysis of academic ophthalmologists in the United States, we found a statistically significant association between industry payments and scholarly impact among ophthalmologists who received these payments. This finding held true even after controlling for factors such as gender, academic seniority, and subspecialty. Additionally, analysis limited to nonresearch payments showed a similarly strong association. While our findings do not indicate causality, we demonstrate a strong association between industry funding and scholarly impact among academic ophthalmologists.

Our findings are consistent with research showing similar associations between industry payments and scholarly impact in other specialties, including otolaryngology, ${ }^{6}$ plastic surgery, ${ }^{4}$ neurosurgery, ${ }^{5}$ transplant surgery, ${ }^{3}$ and oncology. ${ }^{7}$ While research in ophthalmology has previously shown that $\mathrm{H}$-index varies by academic rank and fellowship, ${ }^{17}$ our study is the first to investigate the impact of industry funding on scholarly impact. In addition to confirming these differences in scholarly impact by academic rank and subspecialty, our analysis also extends these findings to show that industry funding modulates these associations. Within subspecialties such as cornea/eternal disease, glaucoma, oculoplastics, pediatric ophthalmology/strabismus, and surgical retina, ophthalmologists receiving greater than $\$ 1,000$ in industry funding had significantly higher mean $\mathrm{H}$-index than those receiving less than $\$ 1,000$. We did not observe these differences in other subspecialties, likely due to limited sample size. For example, only 11 of the 25 ophthalmic pathologists in our sample received payments, and only two of these received greater than $\$ 1,000$ in industry payments; ophthalmic pathologists may also be trained through pathology rather than ophthalmology. Our findings are also consistent with research about gender differences in industry funding of ophthalmologists, again demonstrating that female ophthalmologists receive industry payments considerably less commonly than men and in lower quantities. ${ }^{18,19}$ Finally, our analyses mirror the results 
Table 3 Distribution of general industry payments by payment type and association with $\mathrm{H}$-index

\begin{tabular}{|l|l|l|l|l|l|l|}
\hline $\begin{array}{l}\text { General } \\
\text { payment type }\end{array}$ & $\begin{array}{l}\text { Total } \\
\text { payments } \\
\text { (dollars) }\end{array}$ & $\begin{array}{l}\text { Mean } \\
\text { payment } \\
\text { (dollars) }\end{array}$ & $\begin{array}{l}\text { Number of ophthalmologists paid } \\
\text { (\% of ophthalmologists receiving } \\
\text { general payments) }\end{array}$ & $\begin{array}{l}\text { Mean } \\
\text { H-index } \\
\text { if paid } \\
<\$ 1,000\end{array}$ & $\begin{array}{l}\text { Mean } \\
\text { H-index } \\
\text { if paid } \\
>\$ 1,000\end{array}$ & $p$-Value \\
\hline Food and beverage & 424,588 & 362 & $1,100(94)$ & 14.4 & 21.9 & $<0.001^{* * *}$ \\
\hline Travel and lodging & 955,217 & 814 & $243(21)$ & 16.9 & 24.4 & $<0.001^{* * *}$ \\
\hline Consulting & $4,178,866$ & 3,560 & $204(17)$ & 24.7 & 25.3 & 0.89 \\
\hline Education & $2,918,780$ & 2,486 & $152(13)$ & 14.3 & 23.7 & 0.26 \\
\hline $\begin{array}{l}\text { Speaker fees: } \\
\text { non-CEP }\end{array}$ & $4,351,819$ & 3,707 & $141(12)$ & 16.0 & 26.2 & $0.02^{*}$ \\
\hline Honorarium & 194,095 & 165 & $33(3)$ & 18.0 & 30.9 & $0.048^{*}$ \\
\hline Other & $5,615,058$ & 4,783 & $32(3)$ & 34.6 & 26.0 & 0.32 \\
\hline Speaker fees: CEP & 181,051 & 154 & $28(2)$ & 12.3 & 22.4 & 0.36 \\
\hline Gifts & 45,136 & 38 & $26(2)$ & 21.6 & 21.0 & 0.95 \\
\hline Entertainment & 4,928 & 4 & $15(1)$ & 22.3 & 26.5 & 0.68 \\
\hline
\end{tabular}

Abbreviation: CEP, Continuing Education Program.

Notes: Authors' analysis of general payment data, segregated by general payment type, and differences in mean $\mathrm{H}$-index between physicians receiving less than versus greater than $\$ 1,000$ of payments of each type. Statistical significance indicated by ${ }^{*}$ for $p<0.05,{ }^{* *}$ for $p<0.01$, and ${ }^{* * *}$ for $p<0.001$.

of a previous study that identified an association between National Institutes of Health (NIH) funding and $\mathrm{H}$-index of ophthalmologists. ${ }^{20}$

There are several possible explanations for the association between industry funding and scholarly impact among academic ophthalmologists. Pharmaceutical companies may seek influential ophthalmologists (often referred to as "key opinion leaders") for speaking and consulting engagements, preferentially making payments to ophthalmologists with high scholarly impact. Additionally, ophthalmologists' research may benefit indirectly from industry payments through access to other academic leaders. For example, an ophthalmologist who is paid for a speaking engagement may meet potential research collaborators and gain exposure to new research ideas, which could ultimately lead to increased scholarly impact. Finally, given that consulting fees and travel/lodging represented two of the largest categories of general payments in our analysis, it is possible that ophthalmologists involved in consulting engagements benefit from increased access to research opportunities in collaboration with industry researchers, ultimately increasing their scholarly output.

Given the growing scrutiny of the pharmaceutical industry's impact on medicine, our findings have important implications for the field of academic ophthalmology. Many academic publications and general media outlets have focused on the ways that the pharmaceutical industry can impact prescribing, ${ }^{21}$ disease definitions, ${ }^{22}$ healthcare expenditures, ${ }^{23}$ and medical education. ${ }^{24,25}$ In ophthalmology, industry payments have been shown to impact VEGF prescribing; ${ }^{8,9}$ however, a study of ophthalmology residents showed that while the majority of trainees interact with pharmaceutical representatives, these trainees commonly feel that they are not susceptible to the influence of pharmaceutical promotions. ${ }^{26}$ This discrepancy suggests that clinicians may be subconsciously influenced by industry contributions, and warrants further investigation. Further, industry payments may influence patient perceptions of ophthalmologists: a recent study showed that patients commonly disapprove of their ophthalmologists receiving $\$ 100$ or more in industry payments of any kind. ${ }^{27}$ In our study, the majority of ophthalmologists received this level of payment.

Many professional organizations, including industry organizations such as the Pharmaceutical Research and Manufacturers of America ${ }^{28}$ and physician organizations such as the $\mathrm{AAO}$, have responded to these concerns by publishing guidance on relationships between industry and healthcare professionals and by promoting transparency through requiring conflict of interest (COI) disclosures. For example, AAO requires that anyone who is in a "position to influence content" must disclose their COIs. ${ }^{29}$ This policy requires individuals such as speakers and reviewers to disclose if they have a "financial relationship with a commercial interest and the opportunity to affect the content of CME (Continuing Medical Education) about the products or services of that commercial interest." However, to our knowledge, there are no reporting requirements for payments that are unrelated to an individual's current AAO engagement but that may have influenced that individual's scholarly productivity, such as the nonresearch payments analyzed in our study.

Our findings also have implications for career development in ophthalmology, given the emphasis on producing high-impact scholarly work to achieve academic career progression. Because metrics such as number of publications and citation frequency have historically been used to support academic promotion decisions, knowledge of how industry funding impacts these outcomes is an essential component of understanding career development in academic ophthalmology. 

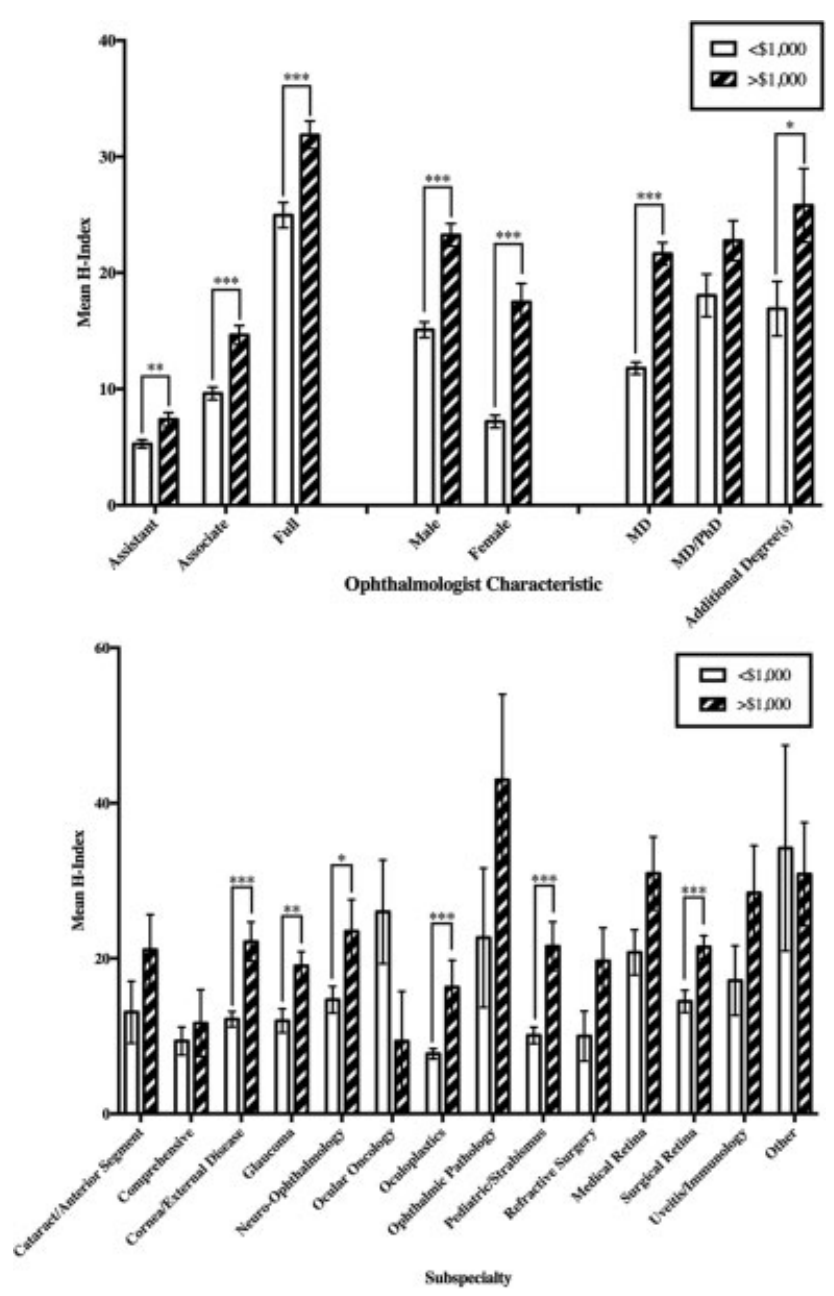

Fig. 2 Mean $\mathrm{H}$-index of ophthalmologists receiving $<\$ 1,000$ versus $>1,000$ of industry payments. Notes: Mean H-index of academic ophthalmologists receiving less than versus more than $\$ 1,000$ in total industry payments, stratified by (top) gender, academic rank, degree (s), and (bottom) subspecialty. Ophthalmologists whose only degree was DO were excluded from the degree analysis due to limited sample size $(n=8)$. Ophthalmologists for whom subspecialty data could not be found were excluded from the subspecialty analysis. Error bars indicate standard error of mean. Statistical significance indicated by ${ }^{*}$ for $p<0.05,{ }^{* *}$ for $p<0.01$, and ${ }^{* * *}$ for $p<0.001$.

There are several limitations to our study. First, our study was not designed to identify a causal relationship between industry funding and scholarly impact. Our study examines an association between these factors, and therefore cannot determine whether industry payments result in higher $\mathrm{H}$-index or whether an ophthalmologist's research productivity leads to greater industry payments, or a combination of both. Second, while the H-index is a widely used surrogate for scholarly productivity, it has several limitations: it does not give credit to heavily cited articles, it is not an optimal tool for making comparisons across different types of research (e.g., basic science research vs retrospective epidemiological research), it favors researchers who publish in developed fields and clinical trials, and it can be artificially inflated by self-citation. ${ }^{30}$ Third, the Scopus database occasionally splits a single author's information into multiple profiles, often after an author switches institutions. In these cases, we chose the profile with the highest $\mathrm{H}$-index, although this approach still underestimates the author's scholarly productivity. Finally, our analysis was limited to industry support and did not control for other sources of funding, such as $\mathrm{NIH}$ grants, which are associated with greater scholarly impact. ${ }^{20}$

In summary, our analysis demonstrates a significant association between industry payments and scholarly impact, even after adjusting for gender, academic rank, and subspecialty. While our study cannot identify a causal relationship, our findings do highlight the important role of industry funding in academic ophthalmology research. As the Open Payments Program accumulates additional data and COI transparency increases, future research should further characterize the relationship between industry funding and scholarly impact in the field of ophthalmology.

Funding

None.

\section{Conflict of Interest}

None.

\section{References}

1 Department of Health and Human Services. Medicare, Medicaid, Children's Health Insurance Programs; Transparency Reports and Reporting of Physician Ownership or Investment Interests; Final Rule. 2013

2 Centers for Medicare \& Medicaid Services. Open Payments. https:// openpaymentsdata.cms.gov/; 2018. Accessed April 1, 2018

3 Ahmed R, Chow EK, Massie AB, et al. Where the sun shines: industry's payments to transplant surgeons. Am J Transplant 2016;16(01):292-300

4 Ahmed R, Lopez J, Bae S, et al. The dawn of transparency: insights from the Physician Payment Sunshine Act in plastic surgery. Ann Plast Surg 2017;78(03):315-323

5 Eloy JA, Kilic S, Yoo NG, et al. Is industry funding associated with greater scholarly impact among academic neurosurgeons? World Neurosurg 2017;103:517-525

6 Svider PF, Bobian M, Lin HS, et al. Are industry financial ties associated with greater scholarly impact among academic otolaryngologists? Laryngoscope 2017;127(01):87-94

7 Kaestner V, Edmiston JB, Prasad V. The relation between publication rate and financial conflict of interest among physician authors of high-impact oncology publications: an observational study. CMAJ Open 2018;6(01):E57-E62

8 Taylor SC, Huecker JB, Gordon MO, Vollman DE, Apte RS. Physician-industry interactions and anti-vascular endothelial growth factor use among US ophthalmologists. JAMA Ophthalmol 2016; 134(08):897-903

9 Singh N, Chang JS, Rachitskaya AV. Open payments database: antivascular endothelial growth factor agent payments to ophthalmologists. Am J Ophthalmol 2017;173:91-97

10 Accreditation Council for Graduate Medical Education (ACGME). List of Programs by Specialty. Available at: https://apps.acgme. org/ads/Public; 2018. Accessed February 1, 2018

11 American Academy of Ophthalmology. Find an Ophthalmologist. Available at: https://secure.aao.org/aao/find-ophthalmologist; 2018. Accessed June 1, 2018

12 Centers for Medicare \& Medicaid Services. Medicare, Medicaid, Children's Health Insurance Programs; Transparency Reports and Reporting of Physician Ownership or Investment Interests. 42 CFR Parts 402 and 403, RIN 0938-AR33, 2013 
e8 Association between Industry Payments to Ophthalmologists and Scholarly Impact Solotke et al.

13 Centers for Medicare \& Medicaid Services. Open Payments: Frequently Asked Questions (FAQS). Available at: https://www.cms. gov/OpenPayments/Downloads/open-payments-general-faq.pdf; 2018. Accessed October 1, 2018

14 Scopus. Author Search. https://www.scopus.com; 2018. Accessed April 1, 2018

15 Hirsch JE. An index to quantify an individual's scientific research output. Proc Natl Acad Sci U S A 2005;102(46):16569-16572

16 Hirsch JE. Does the H index have predictive power? Proc Natl Acad Sci U S A 2007;104(49):19193-19198

17 Huang G, Fang CH, Lopez SA, Bhagat N, Langer PD, Eloy JA. Impact of fellowship training on research productivity in academic ophthalmology. J Surg Educ 2015;72(03):410-417

18 Tringale KR, Hattangadi-Gluth JA. Types and distributions of biomedical industry payments to men and women physicians by specialty, 2015. JAMA Intern Med 2018;178(03):421-423

19 Reddy AK, Bounds GW, Bakri SJ, et al. Representation of women with industry ties in ophthalmology. JAMA Ophthalmol 2016;134 (06):636-643

20 Svider PF, Lopez SA, Husain Q, Bhagat N, Eloy JA, Langer PD. The association between scholarly impact and National Institutes of Health funding in ophthalmology. Ophthalmology 2014;121(01): 423-428

21 Fleischman W, Ross JS. Industry support of physician education in the USA. J Epidemiol Community Health 2017;71(03):213-216

22 Moynihan RN, Cooke GPE, Doust JA, Bero L, Hill S, Glasziou PP. Expanding disease definitions in guidelines and expert panel ties to industry: a cross-sectional study of common conditions in the United States. PLoS Med 2013;10(08):e1001500

23 Donohue JM, Morden NE, Gellad WF, et al. Sources of regional variation in Medicare Part D drug spending. N Engl J Med 2012; 366(06):530-538

24 Austad KE, Avorn J, Kesselheim AS. Medical students' exposure to and attitudes about the pharmaceutical industry: a systematic review. PLoS Med 2011;8(05):e1001037

25 Goodman RL. Medical education and the pharmaceutical industry. Perspect Biol Med 2007;50(01):32-39

26 Wang Y, Adelman RA. A study of interactions between pharmaceutical representatives and ophthalmology trainees. Am J Ophthalmol 2009;148(04):619-622.e3

27 Stein GE, Kamler JJ, Chang JS. Ophthalmology patient perceptions of open payments information. JAMA Ophthalmol 2018;136(12): 1375-1381

28 Pharmaceutical Research and Manufacturers of America (PhRMA). Code on Interactions with Healthcare Professionals. Available at: https://www.phrma.org/codes-and-guidelines/code-on-interactions -with-health-care-professionals; 2017. Accessed October 1, 2018

29 American Academy of Ophthalmology. Financial Disclosure, Conflict of Interest and Bias. Available at: https://www.aao.org/financialdisclosure-conflict-of-interest-and-bias; 2016. Accessed October 1, 2018

30 Choudhri AF, Siddiqui A, Khan NR, Cohen HL. Understanding bibliometric parameters and analysis. Radiographics 2015;35 (03):736-746 